\title{
Opportunities for nurses in the era of electronic health records
}

\section{Tiffany Kelley}

Northeastern University, Boston, USA

Email: Tiffany.kelley@duke.edu

Received 7 September 2013; revised 26 November 2013; accepted 9 December 2013

Copyright (C 2014 Tiffany Kelley. This is an open access article distributed under the Creative Commons Attribution License, which permits unrestricted use, distribution, and reproduction in any medium, provided the original work is properly cited. In accordance of the Creative Commons Attribution License all Copyrights (C) 2014 are reserved for SCIRP and the owner of the intellectual property Tiffany Kelley. All Copyright (C) 2014 are guarded by law and by SCIRP as a guardian.

\begin{abstract}
Nursing leaders are currently faced with opportunities to advance nursing's role in the use of electronic health records (EHRs). Nurse leaders can advance the design of EHRs with nurse informaticists to improve health outcomes of individual and populations of patients.
\end{abstract}

\section{KEYWORDS}

\section{Nurses; Electronic Health Records; Quality and Safety of Care; Informatics; Patient and Population Health Management}

\section{INTRODUCTION}

Today, nurse leaders would be amiss if their attention and efforts were not drawn toward nursing's use of electronic health records (EHRs) for the delivery of quality care [1-4]. Thought leaders began advocating for the use of EHRs in the 1960's [5,6]. The impetus for EHRs continued to grow over the last five decades [7]. However, the adoption and use of EHRs only became a requirement for hospitals and providers in 2009 with the passing of the HITECH Act included in the American Recovery and Reinvestment Act (ARRA) [8]. The HITECH Act sets aside 19.2 billion dollars in federal incentives for US hospitals and provider practices to adopt and use EHRs by 2015 [8-11].

The HITECH Act was a response to the widely held assumption that EHRs will improve the quality of care provided to patients [3,8-11]. As a result, nurse leaders in US hospital and provider practice settings now have new opportunities to advocate for nursing's role in the use of EHRs. Nurse leaders can demonstrate the impact that nurses have on the exchange of information needed for the health care team to provide care. Additionally, the management of information within the EHR will likely impact the health outcomes of individual patients and populations of patients. However, the information needed to manage individual patients and populations of patients may require different design perspectives for the EHR. Finally, nurse leaders will need the expertise of informaticians with a nursing and/or clinical background to support them in working through these opportunities [12]. The purpose of this article is to further describe these opportunities to further advance nursing's role in the EHR as the US prepares for nationwide adoption of EHRs.

\section{NURSES ROLE IN EXCHANGING PATIENT INFORMATION NEEDED FOR CARE}

Nurses represent the largest group of health care professionals $[13,14]$. Nurses in practice spend the largest amount of time with the patient in comparison to other health care professionals. Nurses collect the greatest volume of data about the patient and then must communicate the data through information sources for the benefit of the other health care professionals who depend on the information to deliver care [15]. Yet, how nurses exchange information to and from the patient's health record, remains to be an empirical unknown in the literature [3, 16]. Without such knowledge, nurse leaders are at risk for making EHR design and implementation decisions that may omit essential aspects of nurses' information needs and the associated processes of information exchange for the delivery of patient care [15]. If the processes of nurses' information needs are not fully supported, the flow of information to and from the EHR for timely use by the entire health care team may also present a risk that could impact health outcomes. 


\section{INFORMATION MANAGEMENT DESIGN FOR PATIENT AND POPULATION HEALTH OUTCOMES}

Patient information stored in the EHR must allow for managing patient and population health outcomes [7]. Managing information at the patient level requires the ability for the nurse to assess, plan, intervene, and evaluate individual treatment plans [17]. The nurse must be able to extract a "picture of the patient" from the information that has been stored within the EHR [15]. The population level requires the ability for the health care team to evaluate the data stored within the EHR for relationships that may impact the health outcomes of patient populations [7]. While the EHR will allow for information management on the patient and population level, the representation of the information within the EHR may require different design perspectives to be effective for use by the entire health care team.

\section{PATIENT LEVEL}

On a patient level, nurses in practice settings pride themselves in "knowing the patient" $[3,18,19]$. To know the patient, the nurse must have a breadth of clinical and personal patient information to provide individualized care [20]. The EHR has a role in supporting the nurse with the information needed to know the patient [15]. Nurses must be able to communicate the patient information needed for individualized care in a way that can provide a picture of the patient for other nurses and the extended health care team. However, the structured nature of the data fields commonly found in EHRs may not easily accommodate the contextual aspects of the patient's care needs that require narrative expression by the nurse [15]. As EHRs move toward more "structured" data with less "free text" or narrative representations of the patient's condition, we are potentially risking the nurse's ability to tell the patient's story to the members of the health care team who will be assuming care responsibility of the patient after his or her work day has concluded.

\section{POPULATION LEVEL}

On a population level, data that has previously been collected and stored in the EHR will be aggregated, evaluated and analyzed to evaluate health outcomes of a group of patients. The evaluation of population health outcomes is primarily achieved through the use of a large dataset that contains data from hundreds to thousands of patients. To conduct such evaluations, the data will ideally be stored in a structured format that allows for minimal manipulation of the data to ensure greater integrity of the data. Thus, pre-defined fields with structured vocabularies and terminologies increase the quality of the data when the data is ready for evaluation and analysis. Thus a challenge exists between ensuring that the patient level information needs and population level information needs are met for optimal health outcomes.

\section{NEED FOR INFORMATICIANS}

To address these opportunities, nurse leaders need the expertise of informaticians [12]. Informaticians in health care are trained to integrate computer and information sciences into the clinical disciplines [21]. In addition, informaticians also integrate principles of cognitive science, ergonomics, and human factors into design decisions for new solutions [22]. In health care, informaticians can facilitate the translation of data and information into knowledge through analysis that can be used to effectively manage patient and population health outcomes.

The emergence of EHRs led to an increased awareness and support for informaticians. Nursing and clinical informaticians offer a perspective by which to examine the exchange and management of data and information. Unless nurse leaders currently possess experience and education in informatics, the need to add informaticians to the team will be essential. Nurse leaders may use the scope and standards of nursing informatics practice to establish roles and responsibilities for informaticians within an organization [21].

\section{CONCLUSION}

The increased advocacy and presence of electronic health records in the United States have introduced new challenges in the way in which data are collected, stored, managed, retrieved, and visualized in an effort to improve the overall health for individual patients and populations of patients. For nurses and nursing leadership, attention and efforts must be placed on ensuring nursing's role in care delivery visible in a way that can be extracted to meet the information needs of the many individuals who are involved in the direct delivery of care. Beyond the individual patient, the data found within the EHR can also facilitate new methods and discoveries for managing population level health through national agencies, organizations, and registry groups whose mission is to tackle public health issues that remain to be a burden on individuals, communities and the nation. By partnering with informaticians who have expertise in the health care field, we will be better equipped to approach these challenges.

\section{REFERENCES}

[1] Vogelsmeier, A. and Scott-Cawiezell, J. (2009) The role of nursing leadership in successful technology implementation. Journal of Nursing Administration, 39, 313- 


\section{4. http://dx.doi.org/10.1097/NNA.0b013e3181ae94e2}

[2] Nickitas, D.M. and Kerfoot, K. (2010) Nursing informatics: Why nurse leaders need to stay informed. Nursing Economics, 28, 141-158.

[3] Kelley, T.F., Brandon, D. and Docherty, S. (2011) Electronic nursing documentation as a strategy to improve quality of care. Journal of Nursing Scholarship, 43, 154162. http://dx.doi.org/10.1111/j.1547-5069.2011.01397.x

[4] Kutney-Lee, A. and Kelly, D. (2011) The effect of hospital electronic health record adoption on nurse-assessed quality of care and patient safety. Journal of Nursing Administration, 41, 466-472.

http://dx.doi.org/10.1097/NNA.0b013e3182346e4b

[5] Weed, L.L. (1968) Medical records that guide and teach. New England Journal of Medicine, 278, 593-600. http://dx.doi.org/10.1056/NEJM196803142781105

[6] Dick, R.S., Steen, E.B. and Detmer, D.E. (1997) The Computer-Based Patient Record: An Essential Technology for Health Care. National Academy Press, Washington, D.C.

[7] Institute of Medicine (2012) Health IT and Patient Safety: Building Safer Systems for Better Care. National Academy Press, Washington, D.C.

[8] United States Congress (2009) American recovery and reinvestment act of 2009.

http://www.gpo.gov/fdsys/pkg/BILLS-11hr1eh/pdf/BILL S-111hr1eh.pdf

[9] Blumenthal, D. (2010) Launching HITECH. New England Journal of Medicine, 362, 382-385.

http://dx.doi.org/10.1056/NEJMp0912825

[10] Healthit.gov. (2013) HITECH Act. http://www.healthit.gov/policy-researchers-implementers/ $\underline{\text { hitech-act-0 }}$

[11] HITECH Answers (2013) HITECH Act. http://www.hitechanswers.net/about/about-the-hitech-actof-2009/

[12] McLane, S. and Turley, J.P. (2011) Informaticians: How they may benefit your healthcare organization. Journal of Nursing Administration, 41, 29-35. http://dx.doi.org/10.1097/NNA.0b013e3181fc19d6
[13] Kurtzman, E.T., Dawson, E.M., Johnson, J.E. and Sheingold, B.H. (2010) Nurses should drive health reform. American Journal of Nursing, 110, 11. http://dx.doi.org/10.1097/01.NAJ.0000366028.82909.d8

[14] American Nurses Association (2011) Registered nurses in the United States.

http://www.nursingworld.org/FunctionalMenuCategories/ Abou-

tANA/NationalNursesWeek/MediaKit/NursingbytheNum bers.pdf

[15] Kelley, T.F. (2012) Information Use with Paper and Electronic Nursing Documentation by Nurses Caring for Pediatric Patients (Unpublished doctoral dissertation) Duke University, Durham.

[16] Kelley, T.F. and Brandon, D. (2012) Development of an observational tool to measure nurses' information needs. AMIA Proceedings, 209-213.

[17] Meyer, G. and Lavin, M.A. (2005) Vigilance: The essence of nursing. Online Journal of Issues in Nursing, 10, 8.

[18] Tanner, C.A., Benner, P., Chesla, C. and Gordon, D.R. (1993) The phenomenology of knowing the patient. Journal of Nursing Scholarship, 25, 273-280. http://dx.doi.org/10.1111/j.1547-5069.1993.tb00259.x

[19] MacDonald, M. (2008) Technology and its effect on knowing the patient: A clinical issues analysis. Clinical Nurse Specialist, 22, 149-155. http://dx.doi.org/10.1097/01.NUR.0000311695.77414.f8

[20] Kelley, T.F., Docherty, S. and Brandon, D. (2013) Information sources needed to support knowing the patient. Advances in Nursing Science, 36, 351-363. http://dx.doi.org/10.1097/ANS.0000000000000006

[21] American Nurses Association (2008) Nursing Informatics: Scope and Standards of Practice. American Nurses Association, Silver Spring.

[22] Shortliffe, E.H. and Cimino, J.J. (2006) Biomedical Informatics. 3rd Edition, Springer, New York. http://dx.doi.org/10.1007/0-387-36278-9 